\title{
arena para el hormigón
}

\author{
sand for concrete
}

( Buildfng Industriesn, n." 825, dic. 1958, pág. 42.)

En este trabajo considera el autor sólo las arenas de origen natural, sin tener en cuenta los áridos finos procedentes de piedra machacada, ladrillo o cualquier otro material usado con este fin. Como sabemos, la arena, juntamente con los ladrillos y la grava, es uno de los materiales más utilizados, principalmente en la fabricación de hormigones.

Hasta ahora no se había dado a la calidad de la arena la importancia que requería. En los últimos años la Building Research Station ha variado de criterio respecto al método de clasificar una arena; y en lugar de fijar el tipo de granulometría, que era el princ:pal criterio de calidad, se establece el de superficie específica, que tiene una influencia más directa sobre las características del amasado. Se discuten estos y otros criterios en relación con las normas del proyectista y las posibilidades que tiene el constructor para seleccionar las arenas.

\section{INTRODUCCION.}

Existen diversos tipos de aridos naturales y artificiales para el hormigón. Estos se dividen en áridos gruesos (de granos superiores a $4,7 \mathrm{~mm}$ ) y áridos finos (que pasan por la criba de $4,7 \mathrm{~mm}$ ). Aquí se tratará únicamente de un tipo particular de los áridos finos: la arena natural pro- cedente de mina, río o estuario. Los otros tipos de árido fino, como por ejemplo la arena de piedra machacada, que tamb én se emplea en el hormigón, difiere de la arena natural en su producción y propiedades.

Frecuentemente se da por supuesta la validez de una arena para hacer hormigones; sin embargo, las posibilidades de una arena con buena granulometría no son ilimitadas. Las arenas para hormigones se dividen, según las normas inglesas, en dos categorías: clase $A$, arenas cuya granulometría está comprendida entre límites muy estrechos; y clase $B$, arenas con márgenes granulométricos más amplios, que comprende, por tanto, las arenas más finas. De esto se deduce que las de la clase $\mathbf{B}$ son inferiores.

En 1947 se consideró más importante especificar las granulometrías de las arenas destinadas a hormigones, observándose que era necesario una modificación si se querían amplear las arenas disponibles. Se estudiaron las arenas en explotación $\mathrm{y}$, simultáneamente, la Building Research Station llevó a cabo una investigación sobre el empleo de la fina y su influencia sobre las propiedades del hormigón. Como resultado de este estudio y. de las investigaciones de laboratorio, se propusieron cuatro clases de granulometría para los áridos finos.

El proyectista se enfrenta, frecuente- 
mente, con el problema de especificar la arena que es preciso utilizar; y el usuario tiene que saber seleccionar la más conveniente de entre las diferentes que son válidas para él. El método elemental de especificar una arena como "arena áspera y limpia" no la define, realmente, y es mejor que el productor, proyectista y usuario hablen de arenas que cumplan la Norma. Aunque un proyectista, si lo desea, puede especificar una arena de una determinada zona granulométrica, se comprobará que en muchas partes del país la mayoría de las arenas están comprendidas dentro de una o dos zonas granulométricas. Especiffcar arena de una zona granulométrica de la que no se dispone en la localidad, incrementa los gastos de transporte y hace que no sea posible utilizar los suministros disponibles en la localidad, con las correspondientes desventajas que esto supone.

Sin embargo, la granulometría es sólo un factor. Es necesario considerar también la ausencia de impurezas, la forma y tamaño de las partículas y otras características.

\section{P U R E Z A .}

Las arenas no deben contener particulas muy finas, tales como limos y arcillas (ya que dan lugar a hormigones que precisan un elevado contenido de agua), ni impurezas químicas (las cuales puedan influir sobre el fraguado $\mathrm{y}$ endurecimiento del hormigón o afear su aspecto).

Arcilla y limos.-La arcilla, unas veces, se presenta formando terrones en la arena; en otros casos, las arcillas y limos pueden estar revistiendo las partículas de aquélla. Los terrones de arcilla se aprecian fácilmente, y no deben emplearse en obras de hormigón las arenas que los contengan. Cuando las arcillas o limos se encuentran rodeando las partículas de arena, lo más probable es que la adherencia entre ésta y el cemento sea pobre, siendo también menos durable el hormigón, debido al elevado contenido de agua que es necesario para hacer una mezcla dócil.
Impurezas orgánicas.-Las arenas pueden contener impurezas de origen orgánico que, si están en suficiente cantidad, influyen negativamente sobre el fraguado $\mathrm{y}$ endurecimiento del cemento $\mathrm{y}$, en consecuencia, sobre la resistencia y durabilidad del hormigón.

Piritas de hierro.-Este material se presenta en ciertos depósitos de arena y grava, en cantidades relativamente pequeñas. Las partículas de este mineral, que afloran o están próximas a la superficie del hormigón, lo afean con manchas. Desgraciadamente, no existe en la actualidad ningún método sencillo para determinar la presencia de este mineral perjudicial, y la única precaución que se puede adoptar es la de asegurarse, por previa experiencia, que una determinada arena no contiene esta impureza.

Arenas de mar contaminadas con sales. Cuando las arenas proceden de las costas marítimas o se dragan de los estuarios, es admisible pensar el que no sean adecuadas para su empleo en hormigones, debido a su contenido salino. El contenido de sales en las arenas de mar varía considerablemente; será mayor en las arenas de costa marina que estén por encima de las mareas, rechazándose dichas arenas, a no ser que se laven en agua limpia. La sal de las arenas de mar tienden a producir una ligera corrosión inicial en las armaduras y eflorescencias blancas en la superficie del hormigón. Con una adecuada protección de las armaduras es probable, sin embargo, que no tenga un efecto adverso sobre la calidad del hormigón. La sal, por otro lado, absorbe la humedad de la atmósfera, y su presencia en los muros de hormigón puede dar lugar a las humedades en los edificios.

\section{FORMA I TAMAYO DE LAS PARTICULAS}

De un modo general, en los hormigones, las arenas constituídas por granos redondeados darán lugar a mezclas más dóciles que los que tienen granos de forma irregular, aunque, realmente, esto, en la práctica, no es una caracteristica importante. 
La granulometría de una arena es, probablemente, la propiedad más importante en relación con su empleo en el hormigón.

\section{SUPERFICIK ESPECIFICA.}

Hasta hace poco tiempo se dedicaba la máxima atención a la granulometría del árido del hormigón, $\mathrm{y}$, particularmente, al empleo de las arenas con granulometría continua. Durante estos últimos años se ha utilizado otro principio, respaldado por la investigación experimental, que es el de la superficie específica total de los granos de un volumen determinado, la cual es una característica muy importante, debido a que dicha superficie es la que ha de ser lubrificada por la pasta de cemento y dar lugar a una mezcla dócil.

Debe recalcarse que este principio no contradice al antiguo criterio de granulometría: los dos son complementarios; y juntos dan una mayor posibilidad al dosificar una mezcla. El hecho de que la superficie especifica total de una cantidad determinada de material aumente con la finura es normal. Es importante decir que la superficie por unidad de peso o volumen, se duplica cuando el tamaño (lineal) de las partículas se hace mitad. Así, la superficie específica de las partículas de arena comprendidas entre un par consecutivo de tamices normales, por ejemplo, entre los números 25 y 52 , es, aproximadamente, doble que la de los granos comprendidos entre los dos pares de tamices más proximos, es decir, los números 14 y 25. Es lógico, por tanto, que una arena con una elevada proporción de finos tenga una superffcie específica más alta que una arena gruesa. Por consiguiente, hasta cierto punto, la granulometría de una arena está en relación con su superficie específica, aunque existen muchas curvas granulométricas que corresponden a la misma superficie específica.

Los ensayos han confirmado que la superficie específica de una arena es un factor muy importante que afecta a las propiedades de elaboración de un hormigón. y es preferible que al hacer una clasifica- ción granulométrica de las arenas para el hormigón, se tenga en cuenta este factor.

Sucede asi que, con las arenas naturales adecuadas para hormigonar, la proporción que pasa el tamiz núm. 25 indica un claro índice de la superficie especiflca total, y ésta es la base sobre la cual la Norma inglesa define las cuatro zonas granulométricas. También incluye las tolerancias para evitar que sea rechazada una arena por estar ligeramente apartada de los límites definidos. De la granulometría de 1.070 arenas examinadas en la Building Research Station, un $29 \%$ cayeron fuera de los límites especificados y se consideraron como inadecuadas para utilizarlas en el hormigón. Un $68 \%$ podían dosificarse en una de las cuatro zonas granulométricas, mientras que el $3 \%$ restante, aunque dentro de los límites totales, tuvieron características granulométricas $\mathrm{y}$ no estuvieron comprendidas totalmente en ninguna de las zonas granulométricas, incluso teniendo en cuenta las tolerancias admisibles.

Proporción de áridos finos y gruesos.Para comprender por qué una arena, de cualquiera de las cuatro zonas granulométricas, puede producir un buen hormigón, tenemos que considerar la superficie específlca total combinada de los áridos finos y gruesos. La superficie específica de una arena de la zona 4 será mayor que la de otra de la zona 1 , pero esto puede arreglarse disminuyendo la proporción entre áridos fino y grueso, con objeto de obtener una superficie específica total similar, $y$, por consiguiente, una docilidad parecida. Hay que hacer constar que se consigue sin aumentar la relación agua/cemento, $y$, por consiguiente, sin que se produzcan pérdidas de resistencia en el hormigón.

Como un ejemplo considérese un hormigón 1:2:4 (en peso), en el que se emplea una arena de la zona granulométrica 2. En este caso, el contenido de arena es de un $33 \%$ del árido combinado. Si se sustituye ahora por una arena más fina, de las zonas 3 o 4 , y se mantienen las mismas proporciones de la mezcla y relación agua/cemento, entonces la mezcla será más seca y menos dócil. Si se ajusta 
la docilidad añadiendo más agua, se aumentará la relación agua/cemento $\mathrm{y}$, en consecuencia, se reducirá la resistencia y durabilidad del hormigón. Por el contrario, si se reduce el contenido de arena y el árido grueso correspondiente se aumenta, para que la superficie específica de la combinación de granos sea la misma que en la primitiva mezcla $1: 2: 4$, se conservará la misma docilidad sin aumentar la relación agua/cemento. En consecuencia, aunque se utilice una arena más flna, el hormigón resultante tendrá propiedades similares al hecho con arena gruesa.

Debe, pues, pensarse que, con este método, puede mantenerse la resistencia del hormigón, independientemente de la zona granulométrica de la arena. Por ejemplo, una arena de la zona 4, utilizada en un hormigón normal de mezcla $1: 2: 4$, da una resistencia a compresión, a los veintiocho días, de unos $56 \mathrm{~kg} / \mathrm{cm}^{2}$ más baja que el fabricado con una arena de la zona 2, empleada en una mezcla similar; reduciendo el contenido de arena, correctamente, se obtiene un hormigón de buena calidad.

Se observará que, aunque se use una arena fina en el hormigón, con la relación normal árido fino-grueso $1: 2$, y se produzca un hormigón más débil, este hormigón será adecuado para muchos fines constructivos. Cuando se use una arena. más fina y se quiera obtener un hormigón de alta calidad, entonces deberá ajustarse la relación flno/grueso. En la actualidad, la determinación de la superficie específica y el cálculo exacto del contenido de arena puede hacerse únicamente en laboratorio, pero es de esperar que pronto se disponga de un método de obra que dé resultados suficientemente exactos para la mayoría de los casos. La elección de la relación finos/gruesos más adecuada, forma parte del proceso del proyecto de mezclas, cosa que se sale de la finalidad de esta publicación. Depende de muchos factores, tales como la relación cemento/ árido (las mezclas ricas necesitan un contenido de arena más bajo), el tipo, tamano máximo y granulometría de los áridos utilizados, asi como también de Ios métodos de colocación y compactación.

\section{HORMIGQNES DE GRANULOMETRIA CONTINUA Y DISCONTINUA.}

Cuando una mezcla de hormigón contiene una proporción adecuada de los diversos tamaños de partículas de los áridos, desde los mayores a los más pequeños, se la conoce como una mezcla de granulometría continua. Tal mezcla se consigue mezclando un árido grueso con una arena de la zona 2 . Se obtendrá un hormigón de granulometría discontinua cuando falten ciertos tamaños de granos de los tamices intermedios. Esto sucederá cuando un árido grueso esté mezclado con una arena de la zona 4 , por ejemplo. No hay nada nuevo en el uso de mezclas de horm gón de granulometría discontinua; tienden a presentarse siempre que se utilice una arena fina, incluso en mezclas teóricas tales como la 1:2:4 (aunque en este caso, la mezcla tenga exceso de arena y dé lugar a un hormigón más débil). Actualmente, sin embargo, cuando hablamos de un hormigón de granulometría discontinua, queremos decir uno que ha sido adecuadamente dosificado con una baja proporción de arena, y en estas condiciones obtener un buen hormigón.

Aunque pueden hacerse hormigones de granulometria discontinua que tengan las mismas resistencias que los de granulometría continua, es preciso tener ciertos cuidados adicionales para su utilización en obra. Debido a su bajo contenido de arena, es esencial un buen control de las cantidades que intervienen en la mezcla y se deben adoptar ciertas precauciones al amasarlo y transportarlo para evitar la segregación, especialmente si la mezcla es muy húmeda. Los hormigones de granulometría discontinua son más adecuados en mezclas secas dosificadas para ser moldeados mediante vibración, puesto que, efectivamente, se segregan menos que los de granulometría continua cuando se compactan.

La elección de un hormigón de granulometria continua o discontinua dependerá más de la disponibilidad de áridos en una determinada zona que del hecho de que una determinada granulometría produzca un hormigón mejor que otro. 


\section{UTILIZACION DE LA ARENA EN OBRA.}

Almacenamiento.-Deben adoptarse todos los cuidados para conseguir que la arena apilada en la obra no se contamine con ninguna materia extraña, particularmente arcilla. El suelo del apilamiento será una superficie dura, por ejemplo de hormigón, o losetas de acero con una pequeña pendiente hacia la periferia del apilamiento para que escurran las aguas. Sobre el apilamiento no circularán camiones con las ruedas embarradas, cuando transporten arena. EI agua que contiene la arena constituye un gran problema; y de suceder así, la base del apilamiento deja de actuar como drenaje para el resto. Deberán colocarse tabiques o separaciones provisionales alrededor del apilamiento para separarlo del resto de los áridos de otro tamaño. El apilamiento será tan amplio como sea posible y se hará más bien extenso que de mucha altura.

Mediciones. - La dosiflcación de una mezcla de hormigón se especificará en peso o en volumen; y las cantidades en la obra, también se medirán por los mismos procedimientos. Sea el que sea el método que se utilice, las cantidades especificadas siempre serán de materiales secos al pie de obra, incluso la arena, la cual, generalmente, contiene una gran cantidad de agua. Esto debe tenerse en cuenta, tanto en lo que se reflere a la cantidad de arena a medir como en lo que respecta al agua que hay que añadir en la hormigonera.

Es mejor medir la cantidad de arena en peso: en las grandes obras es el método preferido. Las arenas, por regla general, contienen del $5 \%$ al $10 \%$ de agua en peso, aunque en condiciones extremas puede estar la arena seca por completo o casi saturada. Si no se tiene en cuenta este agua, entonces la mezcla resultante será deficitaria en arena y tenderá a segregarse y formar coqueras. Por tanto, el peso de la arena húmeda debe incrementarse considerando este contenido de agua y se reducirá el agua de amasado de modo que el agua total de la mezcla sea la cantidad especificada. El contenido de agua puede determinarse, bien secando una muestra representativa de la arena $o$ bien por uno de los métodos de determinación del peso. específico. Estos ensayos se harán con la frecuencia que la experiencia indique sean necesarios y después de que se altere alguna de las condiciones, como, por ejemplo, cuando llueva mucho.

En obras pequeñas, la arena, generalmente, se mide, en volumen, utilizando cajas de medida. En estos casos no es probablé que sea necesario conocer el contenido de agua con objeto de ajustar el agua añadida durante el amasado, pero es más importante saber qué efecto tiene el agua sobre su volumen, de modo que la cantidad de arena medida concuerde con la cantidad especificada. El aumento de volumen de una arena depende de su granulometría y de su contenido de agua. Las finas se entumecen más que las gruesas. En éstas, en la zona de un 5 a un $10 \%$ de agua, no hay gran variación de volumen, y lo mejor será adoptar una cifra aprox:mada de un $28 \%$ para la arena fina $y$ de un $17 \%$ para la gruesa, antes que no admitir ninguna tolerancia del total produciendo una mezcla baja en arena.

El volumen adicional de arena puede medirse mejor, aumentando simplemente la profundidad de la caja de dosificación en la cantidad requerida.

F. S. S. 


\section{UTILIZACION DE LA ARENA EN OBRA.}

Almacenamiento.-Deben adoptarse todos los cuidados para conseguir que la arena apilada en la obra no se contamine con ninguna materia extraña, particularmente arcilla. El suelo del apilamiento será una superficie dura, por ejemplo de hormigón, o losetas de acero con una pequeña pendiente hacia la periferia del apilamiento para que escurran las aguas. Sobre el apilamiento no circularán camiones con las ruedas embarradas, cuando transporten arena. EI agua que contiene la arena constituye un gran problema; y de suceder así, la base del apilamiento deja de actuar como drenaje para el resto. Deberán colocarse tabiques o separaciones provisionales alrededor del apilamiento para separarlo del resto de los áridos de otro tamaño. El apilamiento será tan amplio como sea posible y se hará más bien extenso que de mucha altura.

Mediciones. - La dosiflcación de una mezcla de hormigón se especificará en peso o en volumen; y las cantidades en la obra, también se medirán por los mismos procedimientos. Sea el que sea el método que se utilice, las cantidades especificadas siempre serán de materiales secos al pie de obra, incluso la arena, la cual, generalmente, contiene una gran cantidad de agua. Esto debe tenerse en cuenta, tanto en lo que se reflere a la cantidad de arena a medir como en lo que respecta al agua que hay que añadir en la hormigonera.

Es mejor medir la cantidad de arena en peso: en las grandes obras es el método preferido. Las arenas, por regla general, contienen del $5 \%$ al $10 \%$ de agua en peso, aunque en condiciones extremas puede estar la arena seca por completo o casi saturada. Si no se tiene en cuenta este agua, entonces la mezcla resultante será deficitaria en arena y tenderá a segregarse y formar coqueras. Por tanto, el peso de la arena húmeda debe incrementarse considerando este contenido de agua y se reducirá el agua de amasado de modo que el agua total de la mezcla sea la cantidad especificada. El contenido de agua puede determinarse, bien secando una muestra representativa de la arena $o$ bien por uno de los métodos de determinación del peso. específico. Estos ensayos se harán con la frecuencia que la experiencia indique sean necesarios y después de que se altere alguna de las condiciones, como, por ejemplo, cuando llueva mucho.

En obras pequeñas, la arena, generalmente, se mide, en volumen, utilizando cajas de medida. En estos casos no es probablé que sea necesario conocer el contenido de agua con objeto de ajustar el agua añadida durante el amasado, pero es más importante saber qué efecto tiene el agua sobre su volumen, de modo que la cantidad de arena medida concuerde con la cantidad especificada. El aumento de volumen de una arena depende de su granulometría y de su contenido de agua. Las finas se entumecen más que las gruesas. En éstas, en la zona de un 5 a un $10 \%$ de agua, no hay gran variación de volumen, y lo mejor será adoptar una cifra aprox:mada de un $28 \%$ para la arena fina $y$ de un $17 \%$ para la gruesa, antes que no admitir ninguna tolerancia del total produciendo una mezcla baja en arena.

El volumen adicional de arena puede medirse mejor, aumentando simplemente la profundidad de la caja de dosificación en la cantidad requerida.

F. S. S. 